\title{
Australian mortality statistics for rheumatoid arthritis 1950-81: analysis of death certificate data
}

\author{
I P WICKS, J MOORE, AND A FLEMING \\ From the Department of Rheumatology, The Prince Henry Hospital, Sydney, Australia
}

SUMmARY An analysis of mortality related to rheumatoid arthritis (RA) in Australia for the period 1950 to 1981 was undertaken based on information recorded in death certificates. These data include every death over a 32 year period where RA was considered to be the underlying cause. Death from RA was commonly reported $(0 \cdot 17 \%$ of all deaths). The mean age at death from RA in both sexes exceeded that of the general population for most of the period. There was little difference between patients dying of RA and the general population for age at death in the over 50 years' age group. There was a significant decrease in mortality for women dying of RA over the age of 75. RA accounted for more deaths in women than in men (in a ratio of 2·2:1). Men tended to die at a younger age from RA than did women. The impact of RA remained relatively constant in relation both to the total causes of death and to deaths due to other musculoskeletal diseases. There was a significant decline, however, in female RA deaths as a percentage of deaths due to all musculoskeletal diseases. Cohort analysis does not indicate any marked effect from extrinsic factors on mortality due to RA.

There have been no previous reports of national mortality studies of RA over an extended period, though this is one of the most common chronic inflammatory diseases. There are no Australian data on the mortality of this disease. Although other publications have given conflicting results, there appears to be general acceptance that RA does decrease survival. ${ }^{1}$ It is suggested this decreased expectancy may be related to a subgroup with onset at an early age ${ }^{2-4}$ (particularly in men $^{2} 35$ ) or to a subgroup with more severe disease. ${ }^{267}$ Most studies showing decreased life expectancy appear to be biased towards more severe disease, with patients recruited from hospital inpatient or outpatient services. $^{34} 6{ }^{8-12}$ In contrast, studies which include non-hospitalised patients show lower mortality, ${ }^{7} 13$ though this wider sampling is also open to criticism because of possibly inadequate diagnostic criteria or a bias towards milder disease.

Death certificate analysis has been used in previous smaller studies of RA mortality. ${ }^{4714}$ The reliability of information obtained in this way has been questioned, ${ }^{4} 71415$ though the death certificate has been widely used in cause of death

Accepted for publication 3 October 1987.

Correspondence to Dr A Fleming. Department of Rheumatology, Prince Henry Hospital. Little Bay. NSW 2036, Australia. analysis. ${ }^{3} 5$ 7-10 1216 An Australian study outlining some of the epidemiological problems of death certification has recently been reported. ${ }^{17}$

Despite recorded limitations the information derived from death certificate analysis for an entire population over a 32 year period provides an important opportunity to examine aspects of disease process and impact. Our study examines the mortality of RA, its relationship to other causes of death, and the possible effects of environmental factors in the entire Australian population for the years 1950 to 1981 inclusive, as recorded on death certificates.

\section{Methods}

Part one of the death certificate lists a sequence of conditions leading to death, with the underlying cause stated last. This sequence is compiled by the attending doctor ${ }^{18}$ and is then analysed according to a series of rules devised by the World Health Organisation (WHO) ${ }^{19}$ In Australia this function is performed by the Australian Bureau of Statistics and the results published annually in Deaths Australia (1963 to 1981). ${ }^{20}$ Before 1963 the information was published annually in Demography. ${ }^{21}$ Our data for RA cover a 32 year period and were tabulated under the International Classification of Diseases (ICD) 
codes 722 from 1950 to 1967 ('RA and allied conditions'); 712 from 1968 to 1978 ('RA and allied conditions'); and 714 from 1979 to 1981 ('RA and other inflammatory polyarthropathies'). Although RA represents most cases in these categories, other disorders may be included if not covered by another ICD code within class 13 ('Diseases of the bones and organs of movement' 1950 to 1967 ; 'Diseases of the musculoskeletal system and connective tissue' 1968 to 1981). The arrangement of the data for computer analysis has been previously described. ${ }^{22}$

The average age of death is the arithmetic mean. Owing to the relatively small number of deaths involved, fluctuations about the arithmetic mean are to be expected. Trend lines were fitted to the data in Figs 1, 2, 3, 4, and 6 using ordinary least square regression. To compare recorded mortality mor号 specifically with those of the population more likely: to have developed RA, mean age of death for the population over 50 years of age was calculated. Ag巳 specific mortality is the mortality per 100000 fo, each of the five age groups $65-69,70-74,75-79 \frac{5}{2}$ $80-84,85+$. This rate is multiplied by 100000 . Th 8 population chosen to calculate age standardise mortality was that of Australia in 1950).

$\mathrm{Z}$ is the standard normal variate used to test the null hypothesis for each of the 32 years and can bद्ध expressed as follows:

$$
\mathrm{Z}=\left(\overline{\mathrm{x}}_{1}-\overline{\mathrm{x}}_{2}\right) / \sqrt{\frac{S_{1}^{2}}{\mathrm{n}_{1}}+\frac{S_{\underline{2}}^{2}}{n_{2}}}
$$

where $\bar{x}_{1}=$ mean age of death from all causes (ciot
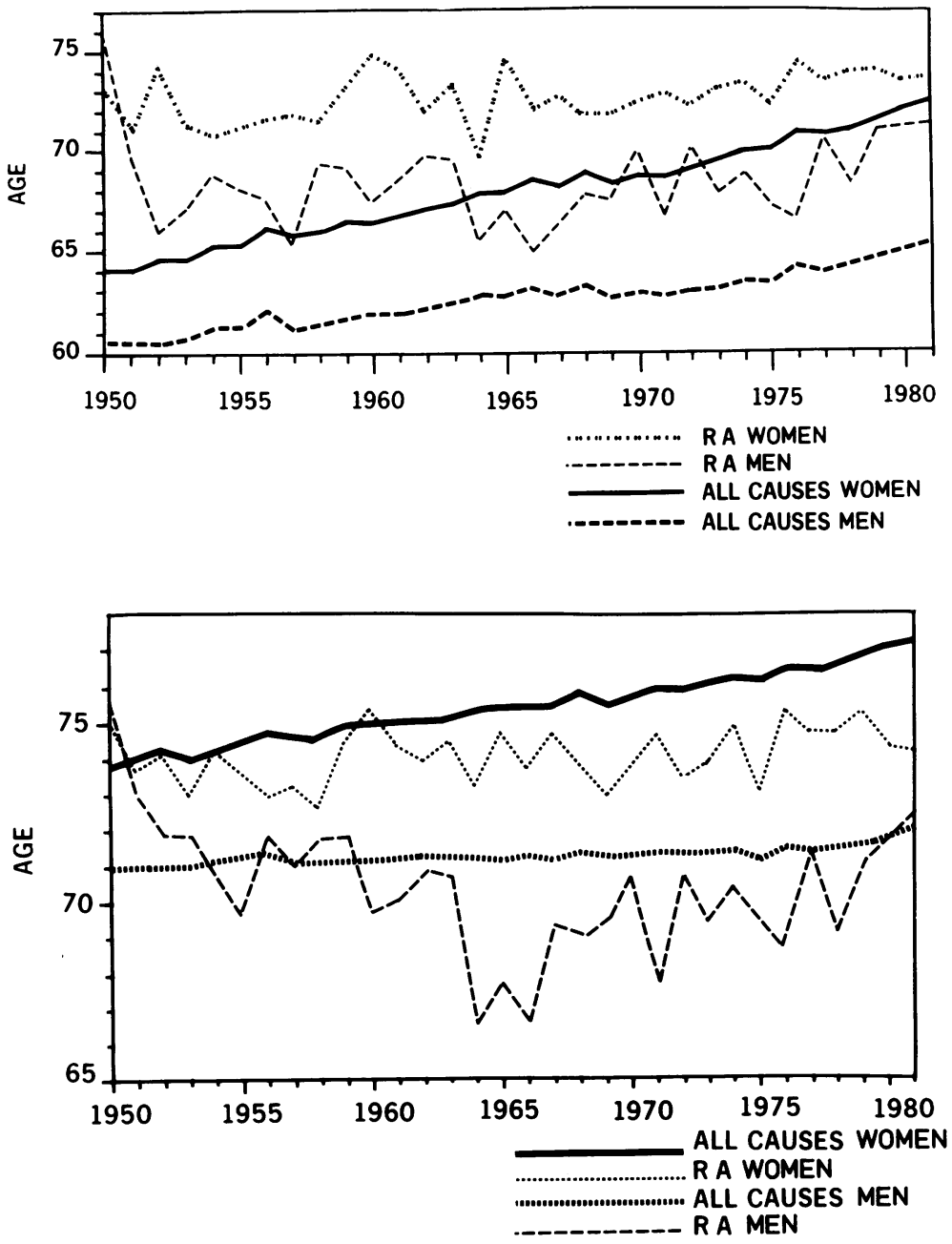

Fig. 1 Mean age of death from $R A$ and from all causes in Australia, by year of death for bot sexes.

Fig. 2 Mean age of death in Australia of those dying over the age of 50 from $R A$ and all causese by year of death for both sexes. 
from all causes, over the age of 50 years); $\bar{x}_{2}=$ mean age of death from RA (or from RA, over the age of 50 years); $S_{1}=$ variance of deaths from all causes (or from all causes, over the age of 50 years); $S_{2}=$ variance of deaths from RA (or from RA, over the age of 50 years); $n_{1}=$ number of deaths from all causes (or from all causes, over the age of 50 years); and $\mathrm{n}_{2}=$ number of deaths from RA (or from RA, over the age of 50 years).

For absolute values of $\mathrm{Z}$ greater than 1.96 , the null hypothesis is rejected with $\mathrm{p}<0 \cdot 05$. In Table 3 the null hypothesis was that there would be no sex difference and hence the sex ratio of deaths due to RA would be 1 . To calculate $\mathrm{Z}$ the actual ratio was subtracted from 1 .

An age, period, and cohort analysis starting with the age groups 50-54 for women and 55-59 for men was performed using the algorithm of Barrett. ${ }^{23}$ Younger age groups did not contain sufficient deaths for valid analysis. As linear trends are not estimable by this technique tests of statistical signifi-

Table 1 Mean age of death from RA for both sexes compared with mean age of death from all causes

\begin{tabular}{|c|c|c|}
\hline \multirow[t]{2}{*}{ Year } & \multicolumn{2}{|l|}{$Z$ value } \\
\hline & Women & Men \\
\hline 1950 & $-5 \cdot 71^{* *}$ & $-7 \cdot 17^{* *}$ \\
\hline 1951 & $-4 \cdot 73^{* *}$ & $-4 \cdot 02^{* *}$ \\
\hline 1952 & $-8 \cdot 99^{* *}$ & -1.85 NS \\
\hline 1953 & $-4 \cdot 62^{* *}$ & $-2 \cdot 58^{* *}$ \\
\hline 1954 & $-3 \cdot 04^{* *}$ & $-3 \cdot 90^{* *}$ \\
\hline 1955 & $-4 \cdot 09^{* *}$ & $-3.93^{* *}$ \\
\hline 1956 & $-4 \cdot 35^{* *}$ & $-2 \cdot 13^{*}$ \\
\hline 1957 & $-4 \cdot 07^{* *}$ & $-1.39 \mathrm{NS}$ \\
\hline 1958 & $-5 \cdot 01^{* *}$ & $-3.99^{* *}$ \\
\hline 1959 & $-5 \cdot 55^{* *}$ & $-3 \cdot 87^{* *}$ \\
\hline 1960 & $-7 \cdot 11^{* *}$ & $-3 \cdot 02^{* *}$ \\
\hline 1961 & $-7 \cdot 08^{* *}$ & $-3 \cdot 75^{* *}$ \\
\hline 1962 & $-3 \cdot 80^{* *}$ & $-4 \cdot 35^{* *}$ \\
\hline 1963 & $-5 \cdot 27^{* *}$ & $-4 \cdot 14^{* *}$ \\
\hline 1964 & -1.07 NS & $-1.91 \mathrm{NS}$ \\
\hline 1965 & $-6 \cdot 58^{* *}$ & $-3 \cdot 02^{* *}$ \\
\hline 1966 & $-2 \cdot 92^{* *}$ & $-0.98 \mathrm{NS}$ \\
\hline 1967 & $-3 \cdot 31^{* *}$ & $-2 \cdot 01^{*}$ \\
\hline 1968 & $-2 \cdot 09^{* *}$ & $-3 \cdot 12^{* *}$ \\
\hline 1969 & $-3 \cdot 19^{* *}$ & $-2 \cdot 74^{* *}$ \\
\hline 1970 & $-3 \cdot 39 * *$ & $-5 \cdot 40^{* *}$ \\
\hline 1971 & $-4 \cdot 11^{* *}$ & $-2 \cdot 88^{* *}$ \\
\hline 1972 & $-3 \cdot 01^{* *}$ & $-4 \cdot 51^{* *}$ \\
\hline 1973 & $-3 \cdot 37^{* *}$ & $-3 \cdot 54^{* *}$ \\
\hline 1974 & $-2 \cdot 87^{* *}$ & $-3 \cdot 54^{* *}$ \\
\hline 1975 & $-2 \cdot 08^{*}$ & $-2 \cdot 38^{* *}$ \\
\hline 1976 & $-3 \cdot 23^{* *}$ & $-1 \cdot 34 \mathrm{NS}$ \\
\hline 1977 & $-2 \cdot 20^{*}$ & $-4 \cdot 24^{* *}$ \\
\hline 1978 & $-2 \cdot 66^{* *}$ & $-3 \cdot 56^{* *}$ \\
\hline 1979 & $-2 \cdot 35^{*}$ & $-5 \cdot 68^{* *}$ \\
\hline 1980 & $-1.50 \mathrm{NS}$ & $-4 \cdot 02^{* *}$ \\
\hline 1981 & $-1 \cdot 31 \mathrm{NS}$ & $-4 \cdot 35^{* *}$ \\
\hline
\end{tabular}

${ }^{*} \mathrm{p}<0.05 ;{ }^{* *} \mathrm{p}<0.01 ; \mathrm{NS}=$ not significant. cance were not applied. The cohort effect reflects that part of the mortality which may be attributed to the five year span in which birth occurred. If an environmental factor operated in a differential way, this might subsequently be reflected in the mortality of a particular cohort(s). The period effect reflects that part of the mortality which may be attributed to the five year span in which death occurred. The period effect is virtually synonymous with the effect of a treatment regimen which influences mortality.

\section{Results}

Mean age of death in RA was significantly greater for both sexes than mean age of death from all causes for most of the period (Fig. 1 and Table 1). For deaths in women over 50 there was a significant difference between RA and the general population in eight of the 32 years, with no significant trend evident (Fig. 2 and Table 2). For deaths in men over 50 there was a significant difference between RA

Table 2 Deaths over 50-mean age of death from $R A$ for both sexes compared with mean age of death from all causes

\begin{tabular}{|c|c|c|}
\hline \multirow[t]{2}{*}{ Year } & \multicolumn{2}{|l|}{$Z$ value } \\
\hline & Women & Men \\
\hline 1950 & $1 \cdot 04$ & $2 \cdot 16^{*}$ \\
\hline 1951 & -0.18 & $1 \cdot 20$ \\
\hline 1952 & 0.20 & 0.38 \\
\hline 1953 & -0.91 & 0.52 \\
\hline 1954 & 0.00 & $-0 \cdot 40$ \\
\hline 1955 & -0.68 & $-1 \cdot 11$ \\
\hline 1956 & $-1 \cdot 64$ & 0.29 \\
\hline 1957 & $-1 \cdot 11$ & -0.04 \\
\hline 1958 & $-2 \cdot 13^{*}$ & 0.48 \\
\hline 1959 & -0.48 & 0.44 \\
\hline 1960 & 0.45 & -1.05 \\
\hline 1961 & -0.70 & -0.85 \\
\hline 1962 & $-1 \cdot 15$ & -0.25 \\
\hline 1963 & -0.59 & -0.32 \\
\hline 1964 & -1.91 & $-3 \cdot 60^{* *}$ \\
\hline 1965 & -0.59 & $-2 \cdot 51^{*}$ \\
\hline 1966 & -1.63 & $-2 \cdot 86^{* *}$ \\
\hline 1967 & -0.59 & $-1 \cdot 35$ \\
\hline 1968 & $-1 \cdot 70$ & $-1 \cdot 74$ \\
\hline 1969 & $-2 \cdot 72^{* *}$ & $-1 \cdot 50$ \\
\hline 1970 & $-2 \cdot 11^{*}$ & -0.40 \\
\hline 1971 & -1.46 & $-2 \cdot 81^{* *}$ \\
\hline 1972 & $-2 \cdot 86^{* *}$ & -0.41 \\
\hline 1973 & $-2 \cdot 21^{*}$ & $-1 \cdot 60$ \\
\hline 1974 & $-1 \cdot 27$ & -0.87 \\
\hline 1975 & $-3 \cdot 11^{* *}$ & $-1 \cdot 30$ \\
\hline 1976 & -1.08 & $-1 \cdot 87$ \\
\hline 1977 & -1.72 & 0.07 \\
\hline 1978 & -1.89 & $-2 \cdot 18^{*}$ \\
\hline 1979 & $-1 \cdot 64$ & -0.53 \\
\hline 1980 & $-3.07^{* *}$ & 0.00 \\
\hline 1981 & $-3 \cdot 35^{* *}$ & 0.48 \\
\hline
\end{tabular}

${ }^{*} \mathrm{p}<0.05 ;{ }^{* *} \mathrm{p}<0.01$. 


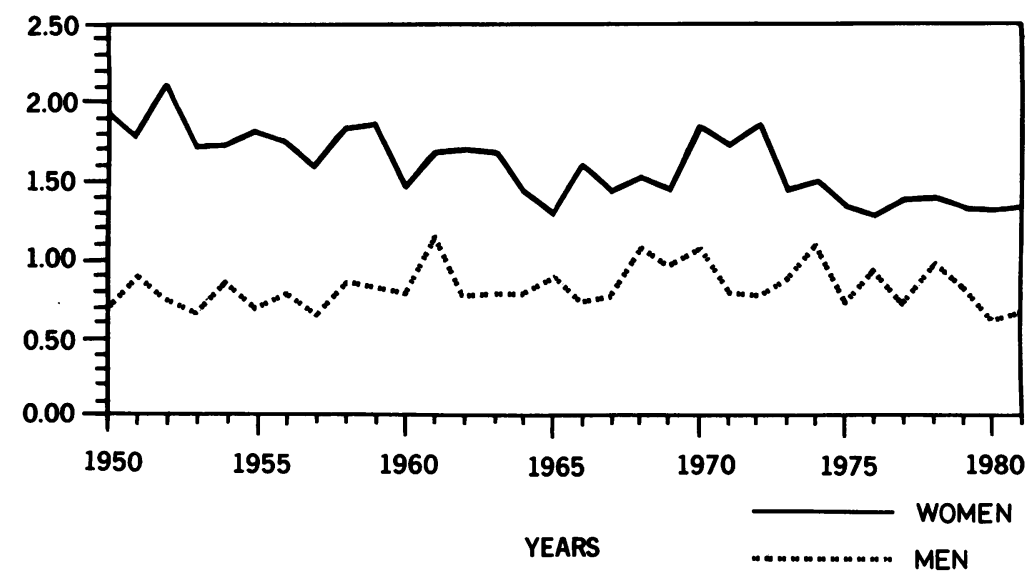

Fig. 3 Age standardised mortali for deaths due to RA in Australia, by year of death for both sexes.

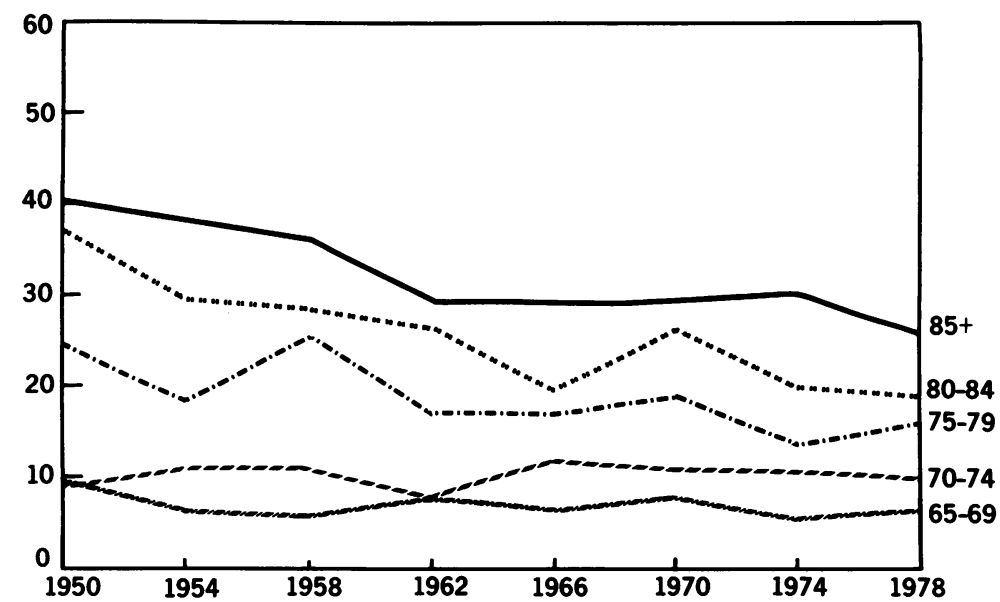

Fig. 4 Age specific mortality for $\stackrel{8}{\Phi}$ women dying of RA in Australia, by four year periods for each of five age groups older than 65 years

4 YEAR PERIOD BEGINNING

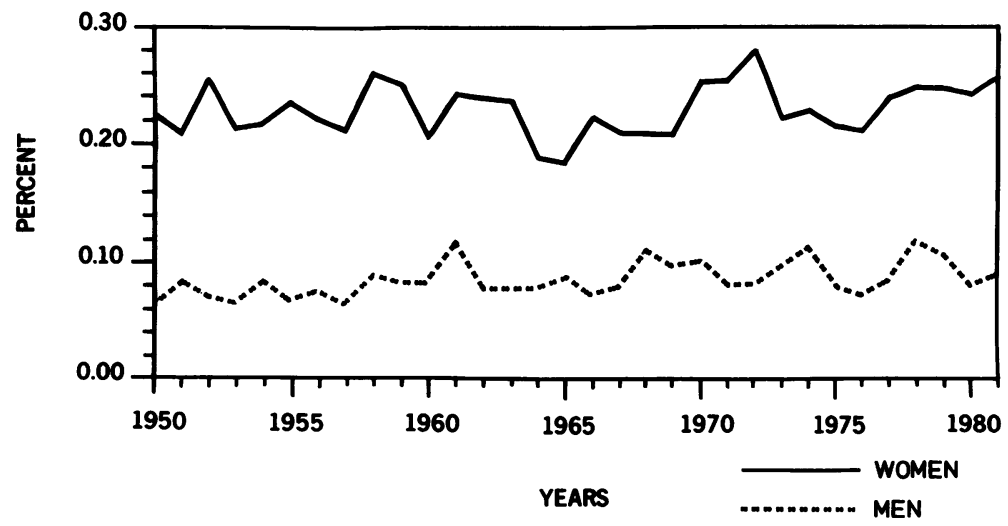

Fig. 5 Percentage of all deaths Australia due to $R A$, by year of $\mathbb{D}$ death for both sexes. 
and the general population in six of the 32 years, with no significant trend evident (Fig. 2 and Table 2).

Women dying of RA live longer than men dying of RA $(p<0.01)$ (Fig. 1). Age standardised mortality for men dying of RA has not changed significantly, but there has been a significant fall $(p<0.01)$ for women dying of RA (Fig. 3). Analysis of age specific mortality shows this improvement for women occurred in the over 75 years' age groups $(75-79, \mathrm{p}<0.05 ; 80-84, \mathrm{p}<0.01 ; 85+, \mathrm{p}<0.01)$ (Fig. 4).

RA is a common cause of death (approximately $0.2 \%$ of all female deaths and $0.1 \%$ of all male deaths), with no significant change in these percent- ages over the 32 year period for either sex (Fig. 5). More women died of RA than men (with an average ratio of $2 \cdot 2: 1$ ), and this ratio has remained relatively constant (Table 3 ). Deaths due to RA as a percentage of deaths from all musculoskeletal diseases have been relatively constant for men, but have shown a significant decline $(\mathrm{p}<0 \cdot 01)$ over the 32 year period for women (Fig. 6).

A cohort and period analysis shows that for neither sex are there any birth cohorts or death periods which differ markedly from others (Fig. 7).

\section{Discussion}

The arguments outlining the limitations inherent in

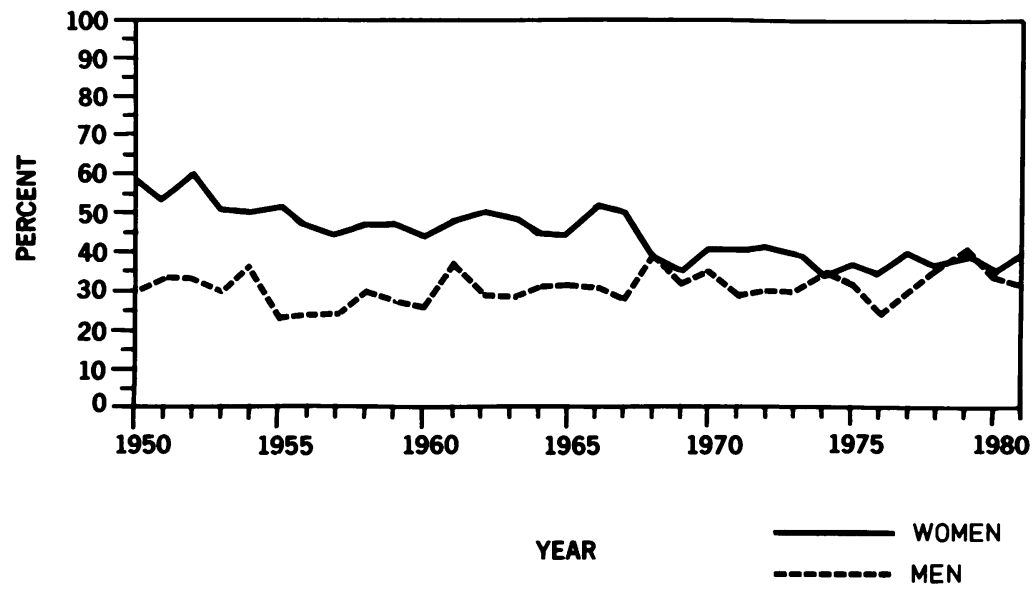

Fig. 6 Deaths due to $R A$ in Australia as a percentage of deaths due to all musculoskeletal diseases (class XIII) by year of death for both sexes.

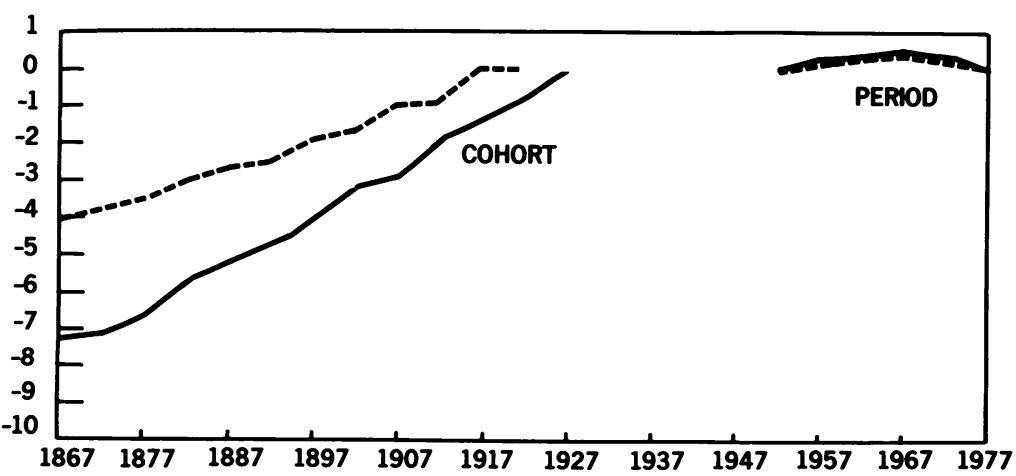

Fig. 7 Cohort of birth and period of death for deaths due to $R A$ in Australia, by central years of birth of cohorts above the ages of 50-54 for women and 55-59 for men, and central year of death. The ordinate is divided into arbitrary units.

CENTRAL YEAR OF BIRTH(COHORT) OR DEATH(PERIOD) 
Table 3 Sex ratio of deaths due to $R A$

\begin{tabular}{lll}
\hline Year & Sex ratio $(F: M)$ & $Z$ value \\
\hline 1950 & $2 \cdot 79$ & $-1 \cdot 01$ \\
1951 & $2 \cdot 00$ & $-0 \cdot 61$ \\
1952 & $2 \cdot 81$ & $-2 \cdot 58$ \\
1953 & $2 \cdot 59$ & $-1 \cdot 51$ \\
1954 & $2 \cdot 05$ & $-0 \cdot 81$ \\
1955 & $2 \cdot 71$ & $-1 \cdot 45$ \\
1956 & $2 \cdot 31$ & $-1 \cdot 33$ \\
1957 & $2 \cdot 60$ & $-2 \cdot 03$ \\
1958 & $2 \cdot 32$ & $-1 \cdot 00$ \\
1959 & $2 \cdot 37$ & $-1 \cdot 68$ \\
1960 & $1 \cdot 98$ & $-3 \cdot 40$ \\
1961 & $1 \cdot 60$ & $-2 \cdot 76$ \\
1962 & $2 \cdot 42$ & $-1 \cdot 04$ \\
1963 & $2 \cdot 39$ & $-1 \cdot 84$ \\
1964 & $1 \cdot 95$ & $-1 \cdot 90$ \\
1965 & $1 \cdot 67$ & $-4 \cdot 53$ \\
1966 & $2 \cdot 49$ & $-3 \cdot 29$ \\
1967 & $2 \cdot 14$ & $-3 \cdot 08$ \\
1968 & $1 \cdot 53$ & $-2 \cdot 27$ \\
1969 & $1 \cdot 70$ & $-2 \cdot 09$ \\
1970 & $2 \cdot 00$ & $-1 \cdot 42$ \\
1971 & $2 \cdot 55$ & $-3 \cdot 64$ \\
1972 & $2 \cdot 76$ & $-1 \cdot 33$ \\
1973 & $1 \cdot 89$ & $-3 \cdot 09$ \\
1974 & $1 \cdot 62$ & $-2 \cdot 40$ \\
1975 & $2 \cdot 15$ & $-2 \cdot 59$ \\
1976 & $2 \cdot 39$ & $-3 \cdot 90$ \\
1977 & $2 \cdot 30$ & $-1 \cdot 47$ \\
1978 & $1 \cdot 70$ & $-3 \cdot 48$ \\
1979 & $1 \cdot 89$ & $-1 \cdot 91$ \\
1980 & $2 \cdot 47$ & $-1 \cdot 26$ \\
1981 & $2 \cdot 30$ & $-1 \cdot 41$ \\
\hline & &
\end{tabular}

the use of death certificate data have been well rehearsed. ${ }^{14}$ 24-27 These may include lack of experience of the doctor completing the certificate; brief contact between the patient and doctor attending the final illness; lack of appreciation of the possible life threatening complications of a disease; lack of postmortem validation; problems of causal sequencing in a complicated illness; inadequate death certificate narrative; changes in the medical concepts of a disease over time; changes in coding practices or classification systems of the WHO. A series of rules has been devised by the WHO in order to interpret the death certificate accurately and improve its epidemiological value. ${ }^{18} 19$ Despite these limitations death certificates remain the most comprehensive method of gathering mortality statistics for the whole community. Furthermore, periodic review of the data obtained from death certificates is a prerequisite to improving the quality of these data. ${ }^{28}$

It is difficult to devise a practical system to study mortality in a chronic relapsing multisystem disorder with a wide range of severity, such as RA, without incurring methodological problems. Most previous reports have included patients drawn primarily from hospital based rheumatology services. This method: contains a case acquisition bias with a possibles tendency for such patients to have a more severeo disease and wcrse outcome. Treatment of sucho patients may also be more aggressive, and the welए recognised toxicity of antirheumatic drugs could itself influence mortality. ${ }^{29}$ Our study is a nationah profile of patients, drawn from both hospital and? community, who were considered to have died from $P$ RA. It is not a study of mortality in all patients previously diagnosed as having RA, nor is it knowm from our data how often RA appears on the deathe certificate other than as the underlying cause of death. Our study minimises factors which can complicate the analysis of death certificates. WEे have taken only deaths due to RA, rather thares examining causes of death in patients known to haveo RA. In addition, we have analysed the annua? national total of deaths due to RA over a prolonged period of time.

Survival in RA has been a controversial issue. In general, studies indicate some reduction in life্ expectancy, more marked for men with early disease onset. Our findings based on death certificate dato in the Australian population over a 32 year perios do not confirm this, and overall the mean age of death from RA has exceeded that of the generas population. The onset of RA appears to be rela 2 tively age specific, however. We therefore analyse deaths over the age of 50 to examine more closelp the population at risk and to minimise the bia inherent in earlier deaths in the general population. (e.g., from trauma). In this group age at death fron RA did not differ significantly from that of the general population. It is of interest that the study o오․ Linos et al, ${ }^{13}$ which came to a similar conclusions was also a more broadly based community study. I addition, Allebeck et al found the death rate in the $25 \%$ of patients who had never been hospitalised fo RA was below that of the whole RA group and les than that of the general population. ${ }^{7} \mathrm{~A}$ recent report from Tasmania suggests that RA in the communito is a less aggressive disease than that seen in hospital setting. ${ }^{30}$ In contrast, it now seems cleâ that mortality is increased among patients with $\mathrm{RA}$ treated in the rheumatology clinic or hospita setting. ${ }^{31} 32$

$\mathrm{RA}$ is a very common disease, with definite $\mathrm{R}$ having a prevalence of approximately $1 \%$ in Caucasians, increasing with age to approach $2 \%$ in mep and $5 \%$ in women over 55 years of age. ${ }^{33}$ Nonethe less, the frequency with which RA was reported as cause of death in our study (approximately $0.17 \%$ was high. It may be that the frequent occurrence of disorder which compromises physical capacity and 
independence in an aging population predisposes to its regular inclusion on death certificates.

Our data show that although RA accounts for more deaths in women, in a ratio which accords with the sex prevalence of RA during life, men with RA die younger. This may reflect the well documented sex difference in overall life expectancy of men and women. ${ }^{34}$ This difference, however, occurs because men die at a younger age of other common diseases, especially ischaemic heart disease. ${ }^{34}$ The lack of any significant improvement in survival of men with RA over a period when life expectancy increased for men in general, plus the failure of the RA male age standardised mortality to fall over this period (as it did for women with RA), may also suggest that RA is a more aggressive disease in men. It has been stated that over 50 years of age the prognosis is worse for women with RA than for men. ${ }^{35}$ Our data do not support this, with a significant fall in the age specific mortality of Australian women with RA greater than 75 years of age occurring over the 32 year period.

The aetiopathogenesis of RA is unclear. It is possible that major environmental effects could be important causes. Similarly, other influences, including the introduction of potent treatment regimens, could subsequently affect mortality. Our analysis, however, shows that for neither sex are there any five year birth cohorts or five year death periods differing markedly from others. This implies a lack of any variable environmental influences on disease process as measured by mortality.

Figures were produced by the Department of Medical Illustration, University of NSW and teaching hospitals.

\section{References}

1 Cosh J A. Survival and death in rheumatoid arthritis. $J$ Rheumatol 1984: 11: 117-9.

2 Rasker J J, Cosh J A. Cause and age at death in a prospective study of 100 patients with rheumatoid arthritis. Ann Rheum Dis 1981; 40: 115-20.

3 Cobb S, Anderson F, Bauer W. Length of life and cause of death in rheumatoid arthritis. $N$ Engl J Med 1953; 249: 553-6.

4 Reah T G. The prognosis of rheumatoid arthritis. Proceedings of the Royal Society of Medicine 1963; 56: 813-7.

5 Uddin J, Kraus A S, Garfield Kelly H. Survivorship and death in rheumatoid arthritis. Arthritis Rheum 1970; 13: 125-30.

6 Duthie J R. Brown P E. Truelove L H, Baragar F D, Lawric A J. Course and prognosis in rheumatoid arthritis-a further report. Ann Rheum Dis 1964; 23: 193-204.

7 Allebeck P, Ahlbom A, Allander E. Increased mortality among persons with rheumatoid arthritis, but where RA does not appear on death certificate. Scand J Rheumatol 1981; 10: 301-6.

8 Mutru O, Laakso M, Isomaki H, Koota K. Ten year mortality and causes of death in patients with rheumatoid arthritis. Br Med J 1985; 290: 1797-9.

9 Monson R R, Hall A P. Mortality among arthritics. J Chronic Dis 1976; 29: 459-67.

10 Lewis P, Hazleman B L, Hanka R, Roberts S. Cause of death in patients with rheumatoid arthritis with particular reference to azathioprine. Ann Rheum Dis 1980; 39: 457-61.
11 Vandenbroucke J P. Hazevoet H M, Cats A. Survival and cause of death in rheumatoid arthritis: a 25 year prospective followup. J Rheumatol 1984; 11: 158-61.

12 Prior P, Symmons D P M, Scott D L, Brown R, Hawkins C F. Cause of death in rheumatoid arthritis. Br J Rheumatol 1984; 23: 92-9.

13 Linos A, Worthington J W, O'Fallon W M, Kurland L T. The epidemiology of rheumatoid arthritis in Rochester, Minnesota: a study of incidence, prevalance and mortality. Am J Epidemiol 1981; 111: 87-98.

14 Atwater E C. Jacox R F. The death certificate in rheumatoid arthritis. Arthritis Rheum 1967; 10: 259.

15 Medical services study group of the Royal College of Physicians of London. Death certification and epidemiological research. Br Med J 1978; ii: 1063-5.

16 Burney P G J. Asthma mortality in England and Wales: evidence for a further increase, 1974-1984. Lancet 1986; ii: 323-6.

17 Nairn J R. Cobbin D M, Fett M J. Adena M A. The quality of cause of death data for young Australian men. Aust NZ J Med 1985; 15: 609-16.

18 World Health Organisation. Medical certification of cause of death: instructions for physicians on use of international form of medical certificate of cause of death. Geneva: WHO, 1979.

19 World Health Organisation. Manual of the international statistical classification of diseases, injuries and causes of death. 9th revision. Geneva: WHO, 1977.

20 Australian Bureau of Statistics. Deaths Australia. Annual bulletins 1963-1981. Canberra: Aust Bur Stat.

21 Australian Bureau of Statistics. Demography. Annual bulletins 1950-1963. Canberra: Aust Bur Stat.

22 Moore J W. A computerised system for Australian mortality statistics. Symposium proceedings of the Statistical Society of Australia. 1985.

23 Barrett J C. The redundant factor method and bladder cancer mortality. J Epidemiol Community Health 1978; 32: 314-6.

24 Kircher T, Nelson J, Burdo $H$. The autopsy as a measure of accuracy of the death certificate. $N$ Engl J Med 1985; 313: 1263-9.

25 Ingemar B, Lindahl B, Allander E. Problems in the classification of cause of death diagnoses affecting the reliability of mortality statistics for rheumatoid arthritis. J Chronic Dis 1985; 38: 409-18.

26 Ingemar B, Lindahl B. The causal sequence on death certificates: errors affecting the reliability of mortality statistics for rheumatoid arthritis. J Chronic Dis 1985; 38: 47-57.

27 Leadbetter S. Semantics of death certification. $J R$ Coll Physicians Lond 1986; 20: 129-32.

28 Carter J R. The problematic death certificate. $N$ Engl J Med 1985; 313: 1285-6.

29 Laakso M, Mutru O, Isomaki H, Koota K. Mortality from amyloidosis and renal diseases in patients with rheumatoid arthritis. Ann Rheum Dis 1986; 45: 663-7.

30 Owen S G, Friesen W T, Roberts M S, Francis H, Flux W. Functional capacity and treatment data from a community based study of patients with rheumatoid arthritis. Ann Rheum Dis 1986; 45: 293-303.

31 Mitchell D M, Spitz P W, Young D Y, Bloch D A, McShane D J, Fries J F. Survival, prognosis, and causes of death in rheumatoid arthritis. Arthritis Rheum 1986; 29: 706-14.

32 Scott D L, Symmons D P M, Coulton B L, Popert A J. Longterm outcome of treating rheumatoid arthritis: results after 20 years. Lancet 1987 ; i: 1108-11.

33 Hochberg M C. Adult and juvenile rheumatoid arthritis: current epidemiologic concepts. Epidemiol Rev 1981; 3: 27-44.

34 Pollard J H. Causes of death in Australia, 1971-1981. Med J Aust 1986; 144: 563-4.

35 Symmons D P M, Prior P, Scott D L, Brown R, Hawkins C F M. Factors influencing mortality in rheumatoid arthritis. $J$ Chronic Dis 1986; 39: 137-45. 